\title{
Agenda Escolar Dia: Aplicação Mobile para Estimulação Cognitiva das Habilidades Preditoras do Desenvolvimento Organizacional do Cotidiano Escolar em Crianças e Adolescentes com Transtorno de Espectro Autista
}

\author{
Danielly G. Leite ${ }^{1}$, Jucelio S. dos Santos ${ }^{2}$, Weiner S. de Lima ${ }^{3}$, Aislânia A. de Araújo ${ }^{1}$ \\ ${ }^{1}$ Universidade Estadual da Paraíba (UEPB) \\ ${ }^{2}$ Universidade Federal de Campina Grande (UFCG) \\ ${ }^{3}$ Instituto Específico de Ensino Pesquisa e Pós-Graduação (IEP) \\ \{gualbertodanielly, jucelio.soares.santos, weinerlim, aislanialves\}@gmail.com
}

\begin{abstract}
Resumo. O objetivo deste artigo é relatar o desenvolvimento de uma aplicação informatizada gamificada para ser utilizada em intervenções escolares de crianças e adolescentes (entre 6 a 14 anos de idade) com Transtorno de Espectro Autista em atividades que envolvem as habilidades sociais, conceituais e práticas. Os principais resultados deste trabalho são: uma análise por meio de estudo bibliográfico sobre o processo de ensino aprendizagem em escolares com Transtorno de Espectro Autista para melhorar a estimulação cognitiva em habilidades preditoras do desenvolvimento organizacional do cotidiano escolar e a concepção da aplicação informatizada gamificada que se especifica, detalhadamente, a estrutura e todo o seu funcionamento.
\end{abstract}

\section{Cenário de Uso}

Entre os diversos transtornos existentes, podemos destacar o Transtorno de Espectro Autista (TEA), que vem sendo cada vez detectado por meio de observações atípicas e nos relatos dos pais, professores e familiares mediante observação clínica do comportamento da criança a partir dos primeiros três anos de idade. O TEA é um grupo de distúrbios do desenvolvimento neurológico e caracterizado por limitações das habilidades sociais, práticas e de comunicação, além de comportamentos estereotipados [Association 2014] [Carvalho and Albuquerque 2003].

Apesar de vários estudos sobre o transtorno, ainda não foi possível identificar qual fator que origina o TEA. Embora não exista, uma teoria detalhada que justifique ou explique o autismo existem diversos estudos que procuram compreender o comportamento social, e o funcionamento cognitivo deste transtorno. Existem diversos sintomas, que vão do comprometimento da fala, dificuldade na comunicação, movimentos repetitivos e hiperatividade. Como consequência deste transtorno, a condução sobre a avaliação e os processos de intervenção tornou-se essenciais. Apesar de requererem muito esforço, os processos devem ser estimulados na fase em que a criança começa o desenvolvimento de habilidades motoras, sociais e práticas que ocorrem antes e durante a fase de alfabetização [Luckasson et al. 2002].

Esta realidade poderia ser melhorada se os professores/pais/responsáveis dispusessem de um recurso que pudesse auxiliar no acompanhamento diário das atividades 
VIII Congresso Brasileiro de Informática na Educação (CBIE 2019)

Anais dos Workshops do VIII Congresso Brasileiro de Informática na Educação (WCBIE 2019)

agendadas e que se estimulasse a atenção e o comprometimento dos alunos na organização da rotina escolar e diária, melhorando assim as habilidades adaptativas sociais, práticas e conceituais.

Com intuito de preservar o bem-estar físico e mental das crianças e adolescentes com TEA, partimos do pressuposto de que elementos de jogos presentes em alguns softwares possam encorajar comportamentos específicos e causar empatia pelo indivíduo. Diversas técnicas podem incentivar um indivíduo no processo de aprendizagem, entre elas, um que pode ser utilizado é o método da recompensa, em que faz parte da categoria de estratégias (procedimento da gamificação que está relacionado com alguma ação realizada pelo o usuário que foi positivo). Os pontos e as medalhas, por exemplos, são os elementos de gratificações presentes em um ambiente gamificado, gerando resultados positivos pela instigação dos usuários dando-lhes recompensas visíveis e com isso gerar motivação [Aires and Leite 2017].

No entanto, ainda que exista uma grande variedade de ferramentas digitais produzidas no mercado com sugestões de sua utilização para a educação, não são todos que estão aptos a serem utilizados como ferramentas auxiliares de ensino-aprendizagem, principalmente quando se trata da aprendizagem de indivíduos com TEA, já que a maioria não apresenta funcionalidades específicas que atendessem às necessidades de um autista, no que diz respeito ao estímulo/acompanhamento de habilidades adaptativas sociais, conceituais e práticas. Percebida essa carência de recursos informatizados que estimulem as habilidades de um indivíduo com TEA, auxiliem os profissionais no acompanhamento diário das atividades e consequentemente autonomiza a rotina da criança ou adolescente com TEA, apresentamos por meio deste artigo a necessidade de endereçar um aplicativo educacional adequado a esse público específico.

\section{Desenvolvimento}

Nesta seção são apresentados os passos dados na construção da "Agenda Escolar DIA". Trata-se de um aplicativo de apoio pedagógico que auxiliará no processo de aprendizado de crianças e adolescentes com TEA em atividades que envolvem habilidades adaptativas sociais, conceituais e práticas. Seu objetivo é organizar, de forma divertida e prática, o cotidiano escolar da criança ou adolescente com tais transtornos a ter uma vida mais autônoma e organizada. Esta agenda possui elementos de gamificação que o torna mais divertida a realização das atividades escolares e, possui elementos que ajuda na comunicação verbal e não verbal, estímulos auditivos e visuais que fará com que a criança ou adolescente estimule os sentidos visual e auditivo ao utilizá-la.

\subsection{Análise de Requisitos}

Foram coletados junto a um informante-chave os requisitos funcionais e não funcionais do sistema, definindo para tanto, um esboço de uma solução a ser implementada que atendesse os requisitos levantados. Essas informações foram levantadas por meio de entrevista com questões abertas, considerando para tanto, a relação do profissional com o tema nas dimensões que contemplam esse estudo e após o término da entrevista, foi desenvolvida uma síntese das principais informações e organizadas em uma tabela de análise por componente. Estas informações nortearam a criação de um projeto por meio de um conjunto de requisitos que gerenciou, para tanto, a sua complexidade. 
VIII Congresso Brasileiro de Informática na Educação (CBIE 2019)

Anais dos Workshops do VIII Congresso Brasileiro de Informática na Educação (WCBIE 2019)

Os requisitos funcionais do sistema são: i) disponibilizar as seguintes telas de acesso público: informações, tutorial e créditos da agenda, solicitação de contato e submissão de pedido de cadastro; ii) disponibilizar as seguintes páginas de acesso pósautenticação para o professor (atualizar/visualizar seus dados, cadastrar/editar aluno, visualizar o desempenho individual do aluno por meio de um relatório, cadastrar/visualizar o horário escolar de turmas ou alunos e visualizar notificações de atividades registradas pelos alunos) e para o aluno (cadastrar/visualizar rotina, cadastrar/visualizar agenda escolar e visualizar horário escolar, dados pessoais, recompensas e notificações de atividades e rotinas registradas); e iii) estabelecer os seguintes requisitos de alto-nível: a agenda deve estimular as seguintes habilidades: habilidades sociais - estimular a habilidade da criança ou adolescente relacionada às aptidões sociais; habilidades conceituais - estimular a habilidade da criança ou adolescente nas aptidões acadêmicas, cognitivas e de comunicação; e habilidades práticas - estimular a habilidade da criança ou adolescente nas aptidões de autonomia.

Os requisitos não funcionais do sistema são: i) portabilidade - a aplicação deverá executar em qualquer plataforma Android; ii) requisitos éticos - a aplicação não apresentará aos usuários quaisquer dados de cunho privativo; iii) requisitos legais - a aplicação deverá atender às normas legais, tais como padrões, leis, tec.; iv) usabilidade este requisito deve oferecer ao usuário interface simples e de fácil utilização para uma boa compreensão do ambiente sob condições específicas para o processo de aprendizagem; v) segurança - a aplicação deve conter um login para utilizar o sistema; vi) confidencialidade - a aplicação deve garantir que as senhas e outros campos de entrada de dados sensíveis necessitam ser mascarados; vii) integridade - a aplicação deve garantir que todos os formulários de entrada e strings necessitam ser validadas frente a um conjunto de entradas aceitáveis, antes de a aplicação aceitá-los para processamento; e viii) interface - a aplicação deve utilizar cores agradáveis para o público infantil e pré-adolescente com TEA. O posicionamento e o espaço dos campos foram planejados com tamanhos adequados para ajudar na acessibilidade e facilitar na utilização do aplicativo caso o usuário possua alguma deficiência física. As imagens foram feitas relacionadas às atividades da rotina e gamificação.

\subsection{Modelo de Análise}

As características que serão descritas nesta subseção referem-se ao perfil do usuário, a sequência de eventos do ambiente gamificado e as tecnologias utilizadas para o seu desenvolvimento.

\subsubsection{Perfil de Usuário}

A Agenda Escolar DIA disponibilizará de 2 (dois) tipos de ambientes de acesso, a saber: um para o usuário-professor e outro para o usuário-aluno. Cada usuário terá o seu ambiente de acesso diferente no aplicativo, em que poderão desempenhar as suas respectivas atividades.

A habilidade esperada para o professor na execução das tarefas é a capacidade de manusear um tablet com sistema operacional Android. Sua função é cadastrar alunos, realizar acompanhamento da agenda e gerar os relatórios de desenvolvimento dos alunos. O aluno, por sua vez, deverá ter as seguintes habilidades: i) capacidade de manusear um 
VIII Congresso Brasileiro de Informática na Educação (CBIE 2019)

Anais dos Workshops do VIII Congresso Brasileiro de Informática na Educação (WCBIE 2019)

tablet com sistema operacional Android; ii) noções básicas do processo de leitura; e, iii) nível de percepção visual, auditiva e motora para realizar os registros corretamente. O grau de instrução requerido ao aluno é estar matriculado no Ensino Fundamental I ou II. Os pais ou responsáveis terá acesso privado dentro ambiente do aluno, que terá a função de acompanhar a rotina, e atribuir recompensas de acordo com o desempenho da criança.

O professor após realizar o seu cadastro, poderá realizar os registros de seus alunos e em seguida deverá passar o acesso (login e senha) ao ambiente para o aluno. O aplicativo vincula um professor a um aluno, em que poderá ter acesso por meio de sua conta os dados do aluno. O professor também terá a responsabilidade de cadastrar o horário escolar do aluno. Ele também poderá criar um grupo da turma ou de alunos e disponibilizar o horário para que todos possam visualizar. No ambiente do professor terá uma tela que poderá acompanhar a assiduidade dos alunos por período. Por fim, o professor avaliará positivamente ou negativamente as atividades nas quais o aluno marcou como concluído.

No ambiente do aluno, o responsável pelo menor poderá cadastrar a rotina das crianças e das atividades para determinados dias e horários, bem como obter informações da gamificação e enviar aviso de resgate de recompensas para o e-mail do pai ou responsável. Dentro do ambiente do aluno possuirá um acesso de controle dos pais, em que eles deverão acessar através de um código que será obtido por meio do professor. Nesse acesso, o responsável fará o registro das recompensas e o valor que deverá ser atingido para que a criança possa resgatá-las.

\subsubsection{Utilização das Tecnologias}

No processo de escolha dos motores de desenvolvimento para aplicativos gamificados foi escolhido o Unity 2D, por ele possuir uma versão gratuito e disponibilizar ferramentas que atende as necessidades de desenvolvimento deste projeto.

No Unity $2 \mathrm{D}$, existe duas formas de realizar um projeto que pode ser utilizado a linguagem C\# ou Javascript. Na agenda DIA, optamos pela linguagem $\mathrm{C}$ que é uma linguagem bastante utilizada e possui uma vasta gama de conteúdo disponível de forma gratuito na internet. Esse motor de desenvolvimento possibilita gerar o executável para multiplataforma, como por exemplo, sistema operacional Android, IOS, entre outras.

Os envios de e-mails automáticos serão feitos através de rotinas utilizando a linguagem de programação PHP (Hypertext Preprocessor). Para realizar o envio automático dos e-mails do aplicativo, será utilizado o serviço do CRON que é um recurso presente no sistema operacional Linux, que realiza a execução automática de acordo com o agendamento de horário e data.

Portanto, o Unity 2D atende aos requisitos do aplicativo visando o baixo custo e a agilidade no desenvolvimento da aplicação, por ser multiplataforma esse motor de desenvolvimento, reduz o custo do projeto.

\subsection{Modelo de Arquitetura}

Esta seção apresenta as justificativas para a escolha do modelo da arquitetura da aplicação e do seu armazenamento, bem como o funcionamento geral da solução e como os vários componentes interagem entre si. 
VIII Congresso Brasileiro de Informática na Educação (CBIE 2019)

Anais dos Workshops do VIII Congresso Brasileiro de Informática na Educação (WCBIE 2019)

A Agenda Escolar DIA é um aplicativo que foi inicialmente desenvolvido para o sistema operacional Android o qual tem o conceito do modelo arquitetural de duas camadas. Esse modelo é organizado com uma camada para o cliente e outra para o servidor. A camada mais superficial é composta pela interface gráfica, e também, tem o código-fonte que trata das requisições ao banco de dados, este é denominado como lógica de negócio. A camada mais inferior é composta pelo servidor que tem a função de armazenar os dados através de um serviço de banco de dados, conforme está disposto na Figura 1.

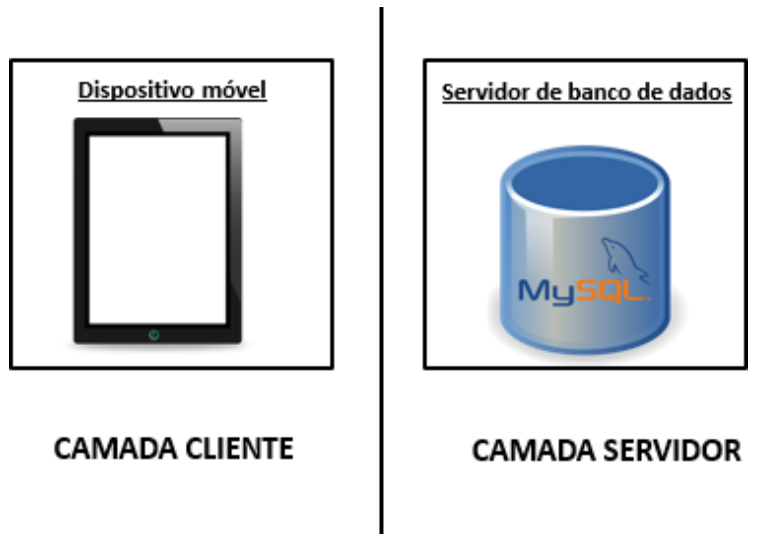

Figura 1. Arquitetura da aplicação "Agenda Escolar DIA"

O banco de dados foi desenvolvido em Mysql, que é um sistema gerenciador de banco dados do tipo relacional. Esse software está localizado em um servidor online, o qual mantem os dados de forma centralizada. Por este motivo facilita o backup aumenta segurança das informações geradas pelos usuários, pois, se estivessem no dispositivo seriam muito mais dificultosa a realização de copias e vulneráveis.

O envio de e-mail que é o mecanismo utilizado para as notificações do aplicativo, foi desenvolvido através de scripts com a linguagem PHP. Estas rotinas serão mantidas em um servidor Linux que está configurado o CRON, este serviço nativo do sistema operacional tem a finalidade de executar tarefas agendadas de forma automatizada.

\section{Apresentação da Agenda Escolar DIA}

A seguir, na Tabela 1 serão apresentadas algumas interfaces do sistema, apresentando como seus usuários são conduzidos nas atividades.

Tabela 1. Interfaces da "Agenda Escolar DIA"

\begin{tabular}{|l|l|l|l|}
\hline Tela & $\begin{array}{l}\text { Passo } \\
\text { Tela inicial da }\end{array}$ & $\begin{array}{l}\text { Eescrição } \\
\text { É apresentado o acesso as seguintes } \\
\text { telas: sobre, créditos e contatos e, } \\
\text { agenda Escolar opções de criar conta e fazer lo- } \\
\text { DIA" } \\
\text { gin. }\end{array}$ \\
\hline
\end{tabular}


VIII Congresso Brasileiro de Informática na Educação (CBIE 2019)

Anais dos Workshops do VIII Congresso Brasileiro de Informática na Educação (WCBIE 2019)

\begin{tabular}{|c|c|c|}
\hline Selo berm vindolo: & $\begin{array}{l}\text { Tela principal do } \\
\text { aluno }\end{array}$ & $\begin{array}{l}\text { É apresentado a página principal do } \\
\text { aluno em que as seguintes funções } \\
\text { são alcançáveis: rotina, agenda, } \\
\text { horário escolar, tutorial, visualizar } \\
\text { dados pessoais, menu de recompen- } \\
\text { sas, notificação de rotina e ativida- } \\
\text { des, e por fim, o campo de código } \\
\text { dos pais. }\end{array}$ \\
\hline MENUDERCCOMPENAS & \multirow[t]{2}{*}{$\begin{array}{l}\text { Tela de menu de } \\
\text { recompensas }\end{array}$} & \multirow[t]{2}{*}{$\begin{array}{l}\mathrm{E} \text { apresentado o menu de recom- } \\
\text { pensas do aluno, composta pela } \\
\text { imagem e nome da recompensa, } \\
\text { data de validade, valor e liberar a } \\
\text { recompensa. }\end{array}$} \\
\hline$a-\infty$ & & \\
\hline 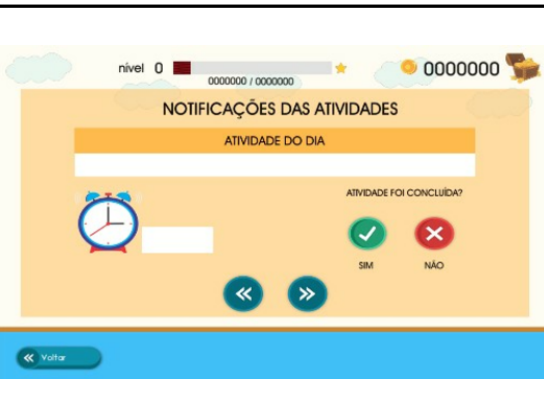 & $\begin{array}{ll}\text { Tela de } \\
\text { notificações } \\
\text { das atividades }\end{array}$ & $\begin{array}{l}\text { É apresentado as notificações das } \\
\text { atividades escolar do aluno, com- } \\
\text { posta por atividade do dia, horário, } \\
\text { botões de atividade concluída e } \\
\text { não concluída. Na seta 'a direita' } \\
\text { leva para as próximas notificações } \\
\text { e a seta 'a esquerda' volta para } \\
\text { notificação anterior. }\end{array}$ \\
\hline (1) & $\begin{array}{l}\text { Tela de rotina do } \\
\text { aluno }\end{array}$ & $\begin{array}{l}\text { É apresentado a rotina diária do } \\
\text { aluno, composta pela visualização } \\
\text { de uma imagem que ilustra uma ati- } \\
\text { vidade da rotina da criança, além } \\
\text { disso, é composto também pela } \\
\text { descrição e horário da rotina. Se } \\
\text { a atividade for concluída o botão } \\
\text { 'verde' deve ser pressionado, caso } \\
\text { contrário o botão 'vermelho'. As } \\
\text { setas de navegação servem para vi- } \\
\text { sualizar as próximas atividades da } \\
\text { rotina. }\end{array}$ \\
\hline 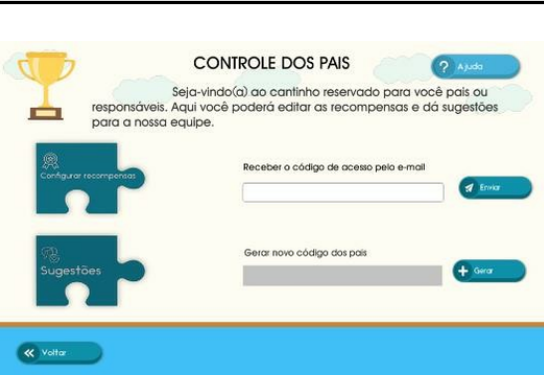 & $\begin{array}{l}\text { Tela de controle } \\
\text { dos pais }\end{array}$ & $\begin{array}{l}\text { É apresentado o controle de acesso } \\
\text { dos pais do aluno, composta por } \\
\text { botões de configurar recompensa e } \\
\text { sugestões, campo e-mail e gerar } \\
\text { novo código de acesso para os pais. }\end{array}$ \\
\hline
\end{tabular}


VIII Congresso Brasileiro de Informática na Educação (CBIE 2019)

Anais dos Workshops do VIII Congresso Brasileiro de Informática na Educação (WCBIE 2019)

\begin{tabular}{|c|c|c|}
\hline Sola bem-vindoco: & $\begin{array}{l}\text { Tela principal do } \\
\text { professor }\end{array}$ & $\begin{array}{l}\text { É apresentado a tela principal do } \\
\text { professor que possui os seguintes } \\
\text { acessos: relatório, aluno, horário } \\
\text { escolar, tutorial, visualizar dados } \\
\text { pessoais e notificações de ativida- } \\
\text { des. }\end{array}$ \\
\hline 的 88 [E & & \\
\hline 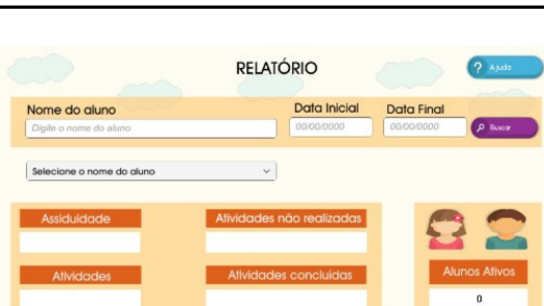 & \multirow[t]{2}{*}{$\begin{array}{l}\text { Relatório do pro- } \\
\text { fessor }\end{array}$} & \multirow[t]{2}{*}{$\begin{array}{l}\text { É apresentado o relatório do aluno } \\
\text { que pode ser gerado mediante al- } \\
\text { guns filtros de pesquisa: nome do } \\
\text { aluno, data inicial e final. O re- } \\
\text { latório pode ser enviado por e- mail } \\
\text { em formato .pdf. }\end{array}$} \\
\hline Q evars & & \\
\hline
\end{tabular}

\section{Considerações Finais}

Foi identificada a carência de aplicações aptas para o apoio do cotidiano escolar de crianças e adolescentes com TEA, conforme discutido neste artigo, lacuna essa que motivou a realização desta pesquisa, com objetivo de desenvolver uma agenda escolar digital para auxiliar no processo de aprendizado de seus usuários em atividades que envolvem habilidades adaptativas sociais, conceituais e prática. Objetivando organizar, de forma divertida e prática, o cotidiano escolar dos seus usuários com tal transtorno a ter uma vida mais autônoma e organizada.

Com intuito de potencializar as habilidades adaptativas sociais, conceituais e práticas, partirmos do pressuposto que a utilização do método de recompensas (pontos e medalhas) possa motivar seus indivíduos na realização das atividades escolares e diárias, viabilizando o processo de amadurecimento de tais habilidades.

O principal resultado deste trabalho até o momento é a própria concepção/desenvolvimento da aplicação gamificada para o cotidiano escolar de crianças e adolescentes com TEA entre 6 a 14 anos de idade para estimular as habilidades adaptativas sociais, conceituais e práticas. Assim, é especificado neste trabalho, o detalhamento da estrutura do funcionamento da aplicação.

Como trabalhos futuros, almeja-se que a aplicação desenvolvida neste trabalho seja utilizada como ferramenta que facilite o cotidiano escolar, para analisá-la como uma prática motivacional para conquistar a atenção e o comprometimento do aluno, e com isso, criar um vínculo de responsabilidade e motivação para o registro e acompanhamento diário das atividades agendadas. De acordo com o cenário apresentado, os próximos passos é responder as seguintes perguntas: uma agenda informatizada e gamificada, por meio do uso do método de recompensas, estimulam habilidades preditoras do desenvolvimento organizacional do cotidiano escolar em crianças e adolescentes com TEA? Com a inserção da prática neste ambiente pode afirmar que os alunos se sentem mais estimulados a realizarem as atividades do cotidiano? 
VIII Congresso Brasileiro de Informática na Educação (CBIE 2019)

Anais dos Workshops do VIII Congresso Brasileiro de Informática na Educação (WCBIE 2019)

\section{Referências}

Aires, S. and Leite, J. C. (2017). Técnicas de motivação para colaboração ao moodle imd. In Anais do VII Workshop sobre Aspectos da Interação Humano-Computador para a Web Social, pages 43-52. SBC.

Association, A. P. (2014). DSM-5: Manual diagnóstico e estatístico de transtornos mentais. Artmed Editora.

Carvalho, E. N. S. and Albuquerque, M. D. M. M. (2003). Nova concepção de deficiência mental segundo a american association on mental retardation retardation-aamr: sistema 2002. Temas em Psicologia, 11(2):147-156.

Luckasson, R., Borthwick-Duffy, S., Buntinx, W. H., Coulter, D. L., Craig, E. M. P., Reeve, A., Schalock, R. L., Snell, M. E., Spitalnik, D. M., Spreat, S., et al. (2002). Mental retardation: Definition, classification, and systems of supports. American Association on Mental Retardation. 